\title{
SIMULASI DISTRIBUSI AIR BERSIH DENGAN ADOBE FLASH
}

\author{
Dwi Kartikasari ${ }^{1}$,Nur Nafi'iyah ${ }^{2}$ \\ ${ }^{1,2}$ Fakultas Teknik Universitas Islam Lamongan, \\ email: dkartika27@gmail.com,mynaff26@gmail.com
}

\begin{abstract}
The use of software in the design of clean water distribution is not new. Commonly software was used specifically was designed for clean water distribution networks, namely Epanet 2.0 and WaterCAD. So that in this research was tried using general software multimedia-based namely Adobe Flash. The stages of making simulation with the Adobe Flash program include: (1) Making a storyline, which is making a layout for planning map for clean water distribution networks. (2) Making images and symbol, including pictures of reservoir location, hamlet locations, village road, while symbol was used to determine the water flow direction from the water source to the reservoir and to each hamlet. (3) making water distribution simulation was described by arrows in the pipe, namely from the water source to the reservoir, also distributed to each village. (4) Finishing stage (finishing), which publishes work files Adobe Flash, namely fla to file in the form of .swf and exe. So that files can be run without installing Adobe Flash software.
\end{abstract}

Key words: Simulation, Clean Water Distribution, Adobe Flash

\begin{abstract}
Abstrak
Penggunaan perangkat lunak dalam desain distribusi air bersih bukanlah hal baru. Umumnya perangkat lunak yang digunakan khusus dirancang untuk jaringan distribusi air bersih, yaitu Epanet 2.0 dan WaterCAD. Sehingga dalam penelitian ini dicoba menggunakan perangkat lunak umum berbasis multimedia yaitu Adobe Flash. Tahapan pembuatan simulasi dengan program Adobe Flash meliputi: (1) Membuat alur cerita, yaitu membuat tata letak untuk merencanakan peta untuk jaringan distribusi air bersih. (2) Membuat gambar dan simbol, termasuk gambar lokasi reservoir, lokasi dusun, jalan desa, sedangkan simbol digunakan untuk menentukan arah aliran air dari sumber air ke waduk dan ke setiap dusun. (3) membuat simulasi distribusi air digambarkan dengan panah di pipa, yaitu dari sumber air ke waduk, juga didistribusikan ke setiap desa. (4) Finishing stage (finishing), yang menerbitkan file kerja Adobe Flash, yaitu fla ke file dalam bentuk .swf dan .exe. Sehingga file dapat dijalankan tanpa menginstal perangkat lunak Adobe Flash.
\end{abstract}

Kata Kunci: Simulasi, Distribusi Air Bersih, Adobe Flash

\section{PENDAHULUAN}

Flash adalah program grafis yang diproduksi pertama kali oleh Macromedia corp, yaitu sebuah vendor software yang bergerak dibidang animasi web. Macromedia Flash pertama kali diproduksi pada tahun 1996. Macromedia flash telah diproduksi dalam beberapa versi. Versi terakhir dari Macromedia Flash adalah Macromedia flash 8. Sekarang Flash telah berpindah vendor ke Adobe (Izham Dedy, dalam http://www.ilmukomputer.com). Adobe Flash Professional CS6, merupakan software yang dirancang untuk membuat animasi berbasis vector 
dengan hasil yang mempunyai ukuran yang kecil. Awalnya software ini memang diarahkan untuk membuat animasi atau aplikasi berbasis internet. Tetapi pada perkembangannya banyak digunakan untuk membuat animasi atau aplikasi yang bukan berbasis internet. Adobe Flash Professional CS6 dapat digunakan untuk mengembangkan game atau bahan ajar seperti kuis dan simulasi. Penggunaan Adobe Flash untuk animasi atau pembuatan bahan ajar interaktif tidaklah sulit, tool-tool yang tersedia cukup mudah digunakan. Beberapa template dan komponen juga sudah disediakan dan siap digunakan (dikutip dari https://ikashofiani.files.wordpress.com/2012/05/modul-pelatihan-adobe-flash

cs3professional.pdf). Pada penelitian ini penggunakan software Adobe Flash digunakan sebagai simulasi sistem distribusi air bersih di Desa Mojosari Kecamatan Mantup. Pemakaian software dalam perancangan distribusi air bersih bukanlah hal baru. Software yang umum digunakan memang dirancang khusus untuk jaringan distribusi air bersih, yaitu Epanet 2.0 dan WaterCAD. Sehingga dalam penelitian ini dicoba menggunakan software umum yang berbasis multimedia yaitu Adobe Flash.

\section{METODE PENELITIAN}

\subsection{Objek Penelitian}

Objek yang digunakan sebagai bahan simulasi adalah jaringan distribusi air bersih di Desa Mojosari Kecamatan Mantup.

\subsection{Pengumpulan Data}

Pengumpulan data berupa data primer dan data sekunder. Data primer merupakan data hasil peninjauan langsung di lokasi kegiatan. Data primer yang dibutuhkan dalam penelitian adalah data hasil pengukuran di lapangan sesuai kondisi Desa Mojosari. Sedangkan data sekunder merupakan data dari internet dan referensi lain yang berhubungan pada penelitian ini.

\subsection{Pengolahan Data}

Tahapan pembuatan simulasi, adalah sebagai berikut:

(a) Pembuatan alur cerita

Yaitu menentukan konsep dan alur perencaaan yang akan dikerjakan. Tahapan ini dimulai dengan pembuatan layout peta jaringan distribusi air bersih. Pembuatan layout sesuai data peta Desa Mojosari.

(b) Pembuatan gambar dan simbol

Gambar dan simbol yang dibuat disesuaikan dengan cerita yang dibuat. Maka dalam simulasi ini diperlukan gambar lokasi waduk, lokasi masing-masing dusun, jalan desa, dan lain-lain. Simbol yang digunakan menentukan arah aliran air dari sumber air ke tandon selanjutnya menuju ke 
masing-masing dusun.

(c) Tahap pembuatan simulasi

Tahapan pembuatan simulasi disesuaikan arah aliran air. (d) Tahap penyelesaian (finishing) Tahap akhir simulasi yaitu proses penyimpanan bentuk file Adobe Flash ke bentuk file .swf dan .exe sehingga nantinya file bisa dijalankan tanpa instal program Adobe Flash.

\section{HASIL DAN PEMBAHASAN}

Pembuatan simulasi menggunakan software Adobe Flash Professional CS6. Dalam pembuatan simulasi distribusi air bersih dengan Adobe Flash, meliputi langkah sebagai berikut:

(a) Pembuatan alur cerita atau alur aliran air Desa Mojosari.

Pembuatan alur aliran air dimulai dari pembuatan layout Desa Mojosari, yang meliputi Dusun Mojoroto, Dusun Belud, Dusun Sendangsari dan Dusun Sidobinangun. Selanjutnya dibuat alur aliran air dari waduk desa menuju masing-masing dusun wilayah Desa Mojosari.

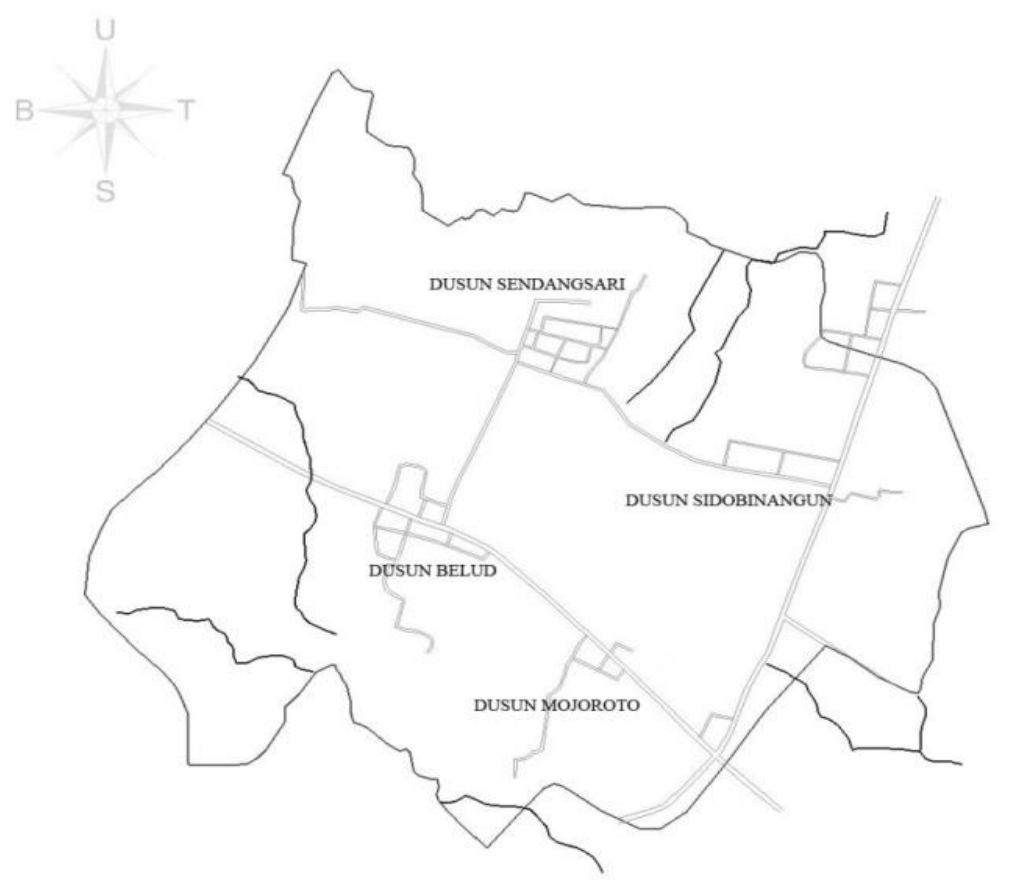

Gambar 1. Peta Desa Mojosari 


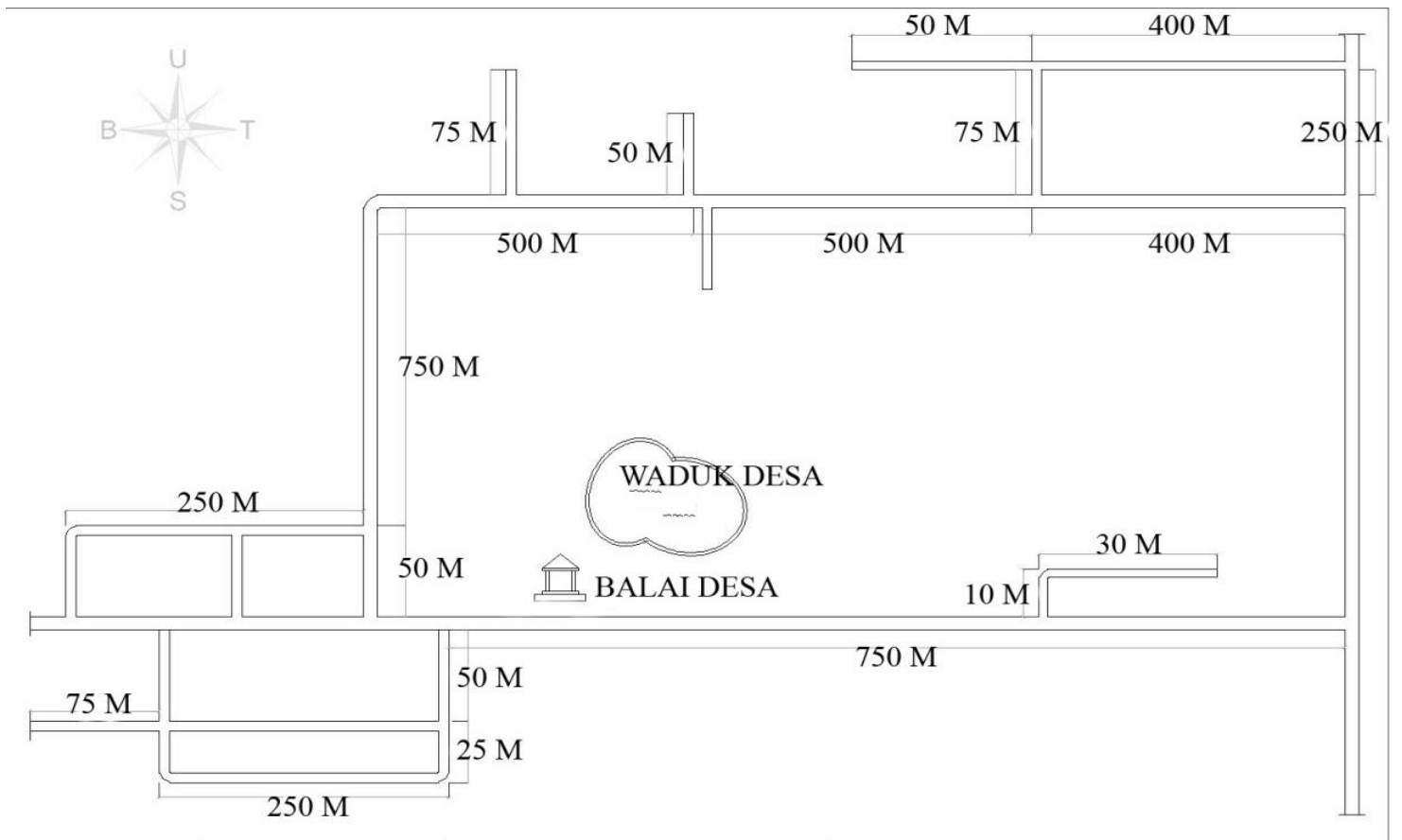

Gambar 2. Layout Desa Mojosari

(b) Pembuatan gambar dan simbol untuk melengkapi bagian multimedia interaktif

Pengumpulan bahan, berupa gambar dan simbol, diperlukan untuk membuat alur distribusi air bersih. Pembuatan layout peta desa, meliputi: gambar per dusun, sumber air, tandon, jalan desa, pipa dan alur air. Symbol-symbol ini dapat dilihat di jendela Library di software Adobe Flash.

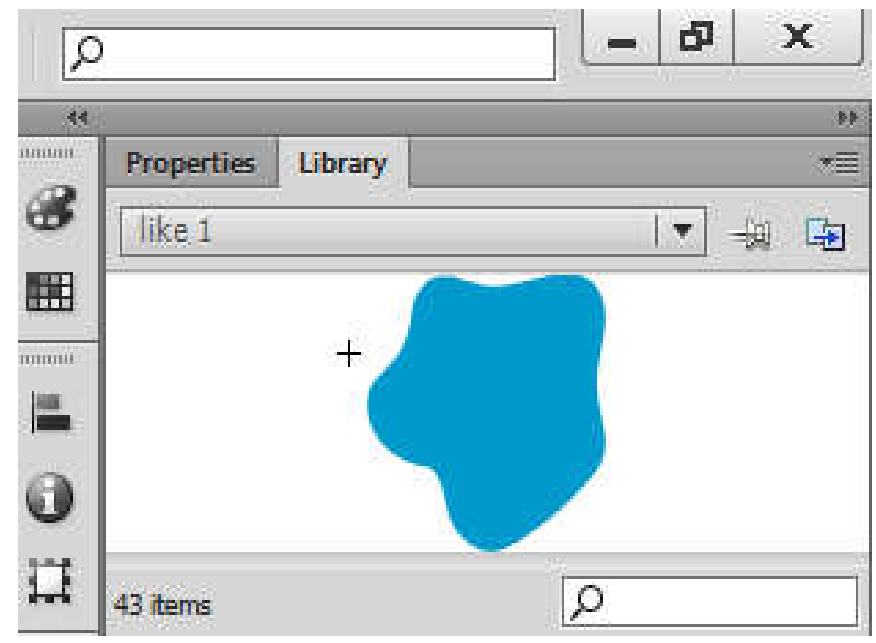




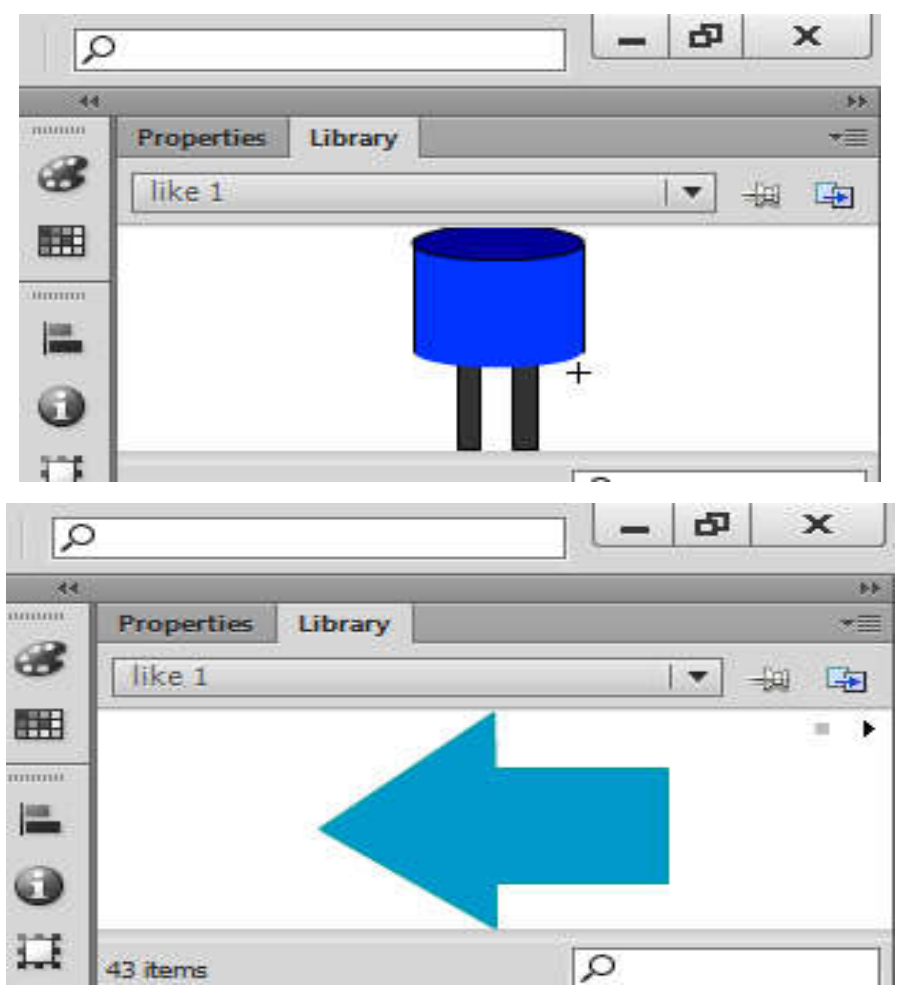

Gambar 3. Pengumpulan Gambar dan Simbol

(c) Tahap pembuatan simulasi

Alur aliran air dimulai dari pengambilan air dari sumber air yang diambil dari waduk Desa

Mojosari. Air dipompa dari sumber air ke tangki/tandon sebagai penampung air. Selanjutnya dari tandon didistribusi ke masing-masing dusun melalui pipa jaringan distribusi. Distribusi Air digambarkan dengan tanda panah yang berada didalam pipa, yaitu mulai dari sumber air ke tandon, serta terdistribusi ke masing2 desa, Simulasi ini dijalankan dengan Adobe flash, yaitu 24 fps (frame per-second). 


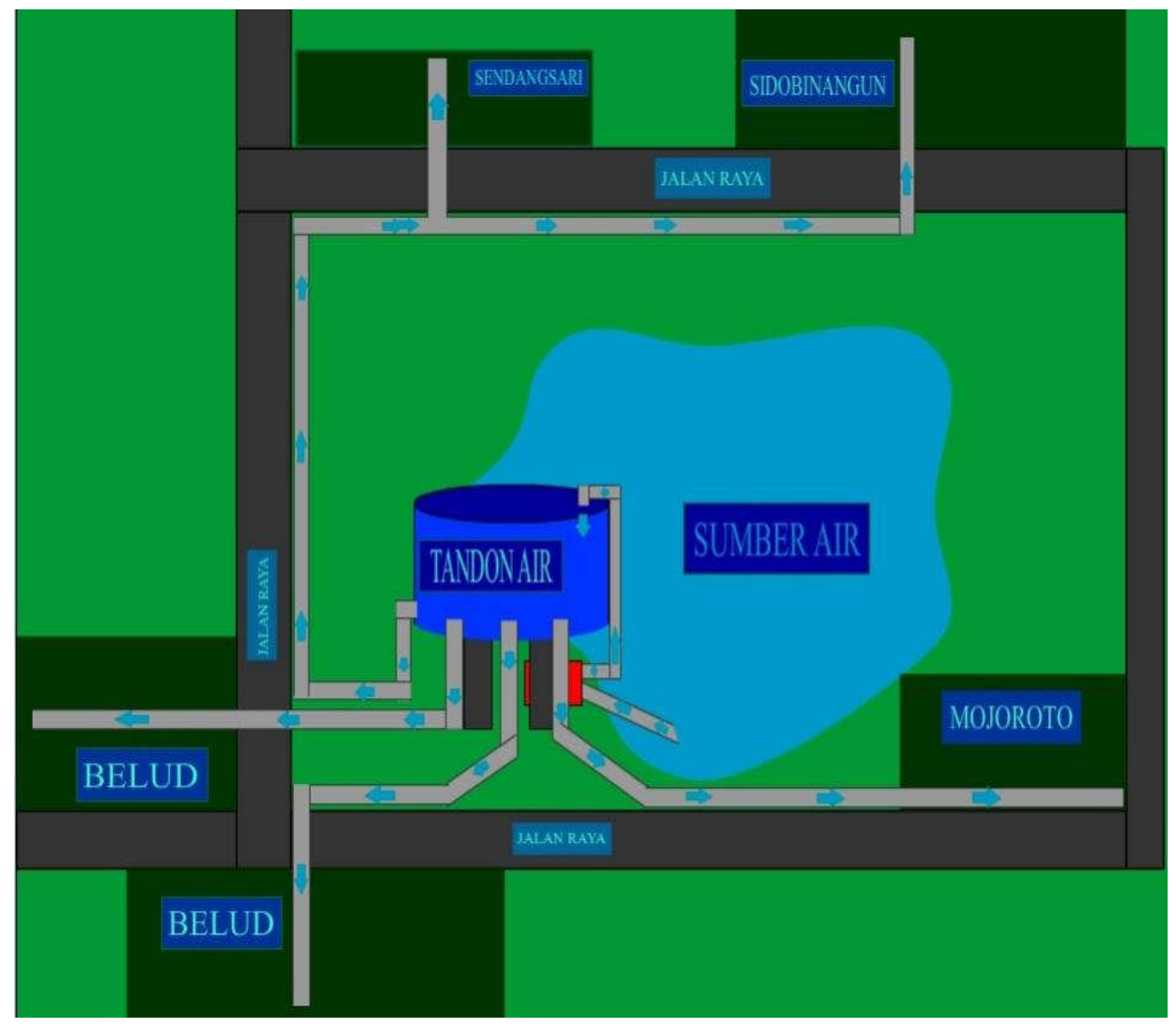

Gambar 4. Simulasi Distribusi Air Bersih

(d) Tahap penyelesaian (finishing)

Tahap akhir dalam pembuatan simulasi yaitu dengan mempublish file kerja Adobe Flash yaitu .fla ke file dalam bentuk .swf dan .exe. Sehingga file dapat dijalankan tanpa melakukan instalasi software Adobe Flash. Berikut langkah-langkah untuk mempublish file kerja adobe flash (.fla) ke file aplikasi (.exe):

(1) pilih menu "File",

(2) pilih sub menu "Publish Preview", kemudian

(3) pilih "Projector". 


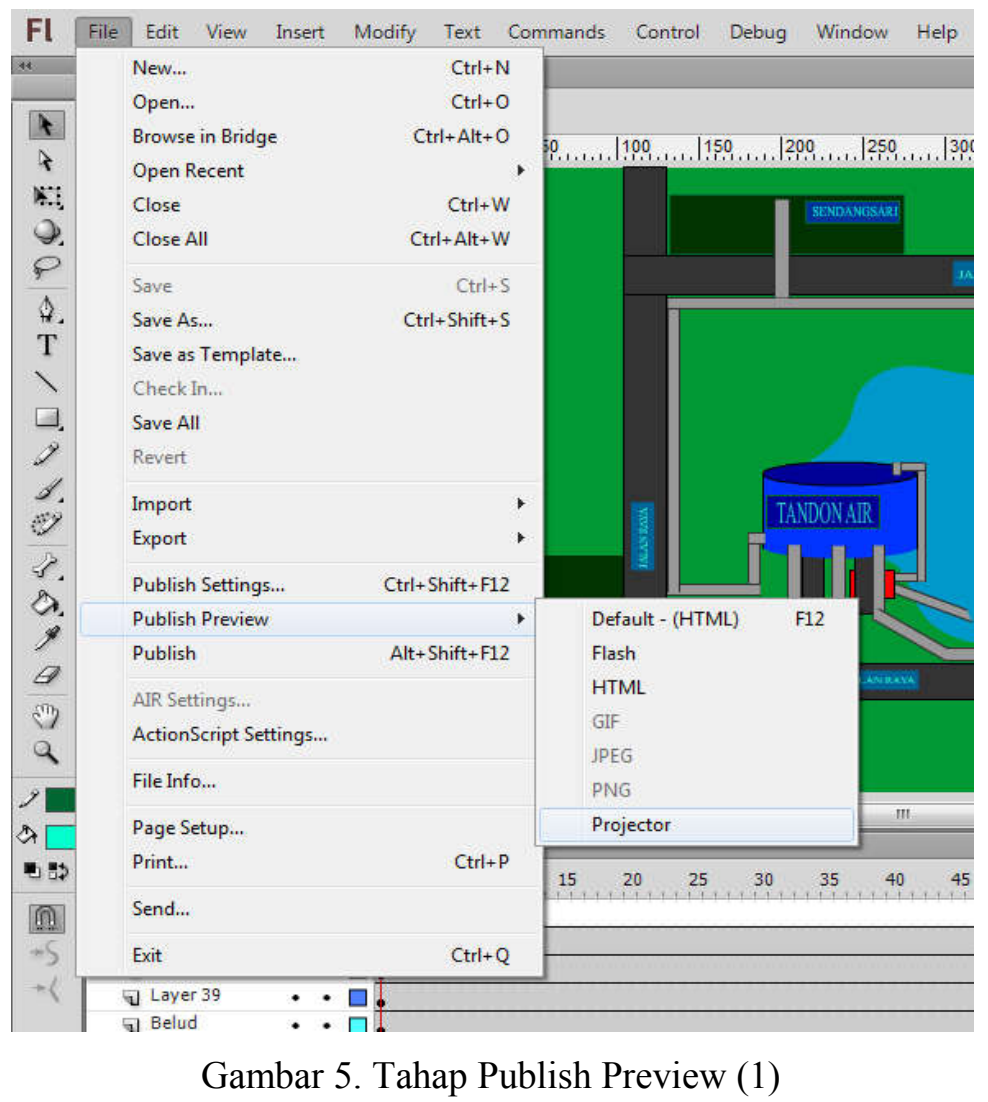

(4) ditunggu sebentar untuk proses publish, kemudian akan keluar hasil publishnya.

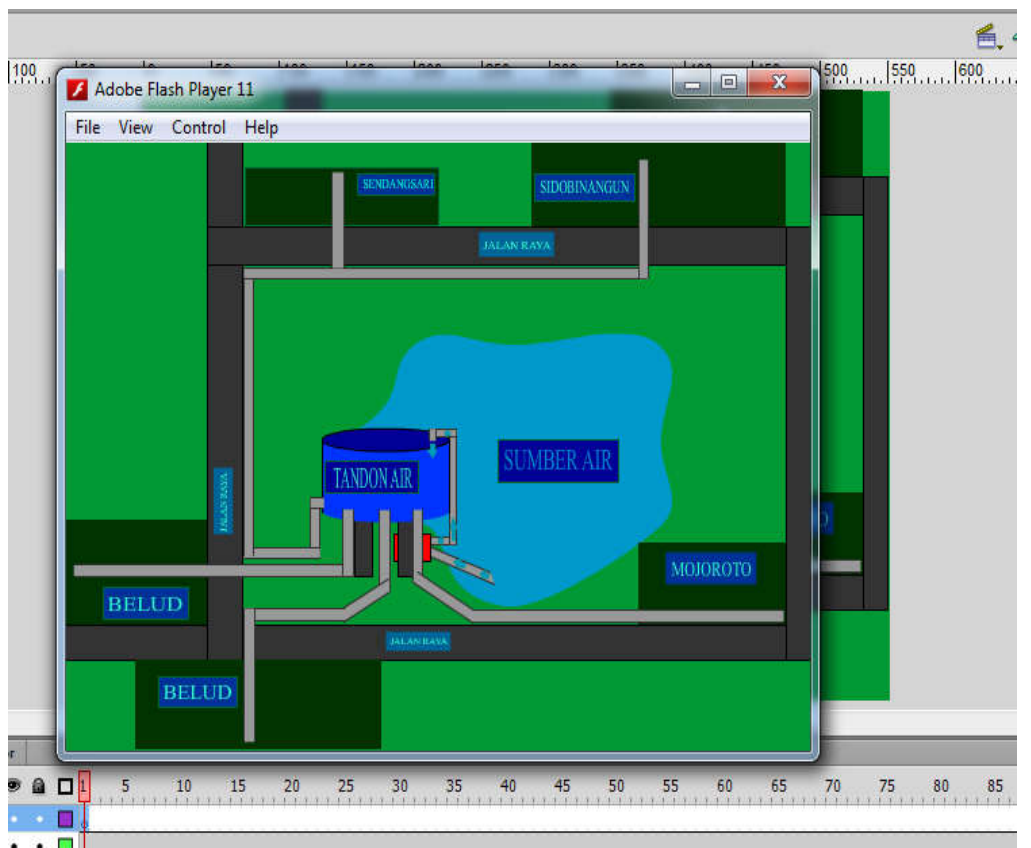

Gambar 6. Tahap Publish Preview (2)

(5). kemudian cek di folder, akan ada file baru dengan type file "Aplication" yang berekstensi .exe. 


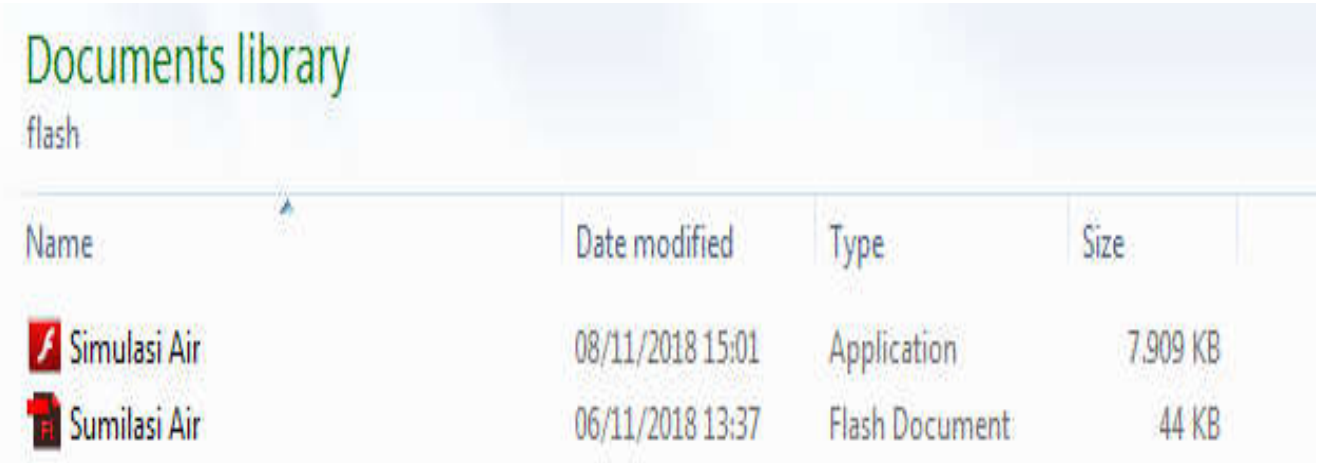

Gambar 7. Tahap Akhir Penyimpanan

\section{KESIMPULAN}

Kesimpulan dalam penelitian ini adalah sebagai berikut:

1. Dalam pembuatan simulasi distribusi air bersih selain menggunakan program yang dirancang khusus untuk jaringan distribusi air bersih, bisa juga menggunakan program umum berbasis multimedia seperti Adobe Flash.

2. Tahapan pembuatan simulasi dengan program Adobe Flash antara lain:

a. Pembuatan alur cerita, yaitu pembuatan layout peta perencanaan jaringan distribusi air bersih

b. Pembuatan gambar dan simbol, meliputi gambar lokasi waduk, lokasi dusun, jalan desa, sedangkan simbol digunakan untuk menentukan arah aliran air dari sumber air ke tandon dan menuju ke masing-masing dusun.

c. Pembuatan simulasi

d. Tahap penyelesaian (finishing)

\section{REFERENSI}

[1] Anonim, 2012, Modul Pelatihan Pembuatan Media Pembelajaran Menggunakan Adobe Flash CS3 Professional, dalam http://ikas hofiani. files. Wordpress.com

[2] Izham, Dedy, 2013, Cara Cepat Belajar Adobe Flash, dalam http://ilmukomputer.com

[3] Lufira, R. D., Suhardjono, S., \& Marsudi, S. (2012). Optimasi Dan Simulasi Sistem Penyediaan Jaringan Air Bersih Di Kecamatan Kademangan Kabupaten Blitar. Jurnal Teknik Pengairan, 3(1), 6-14.

[4] Junedi, A. (2016). Simulasi dan Perbandingan Distribusi Aliran Air Bersih dengan 
Menggunakan Software Pipe Flow Expert pada Perumahan PT. INALUM Power Plant, Paritohan.

[5] Sudirman, A. (2012). Evaluasi Pipa Jaringan Distribusi Air Bersih di Kabupaten Maros dengan Menggunakan Software EPANET 2.0.

[6] Hidayati, N., Ismoyo, M. J., \& Purwati, E. (2014). Aplikasi Software Watercad untuk Perencanaan dan Pengembangan Sistem Penyediaan Air Bersih PDAM Singosari. Jurnal. Jurusan Teknik Pengairan, Fakultas Teknik, Universitas Brawijaya, Malang.

[7] Andika, R. D., \& Kamil, I. M. (2010). Permodelan Sistem jaringan Distribusi Air Minum: Studi Kasus Distrik Majasem, Cirebon.

[8] Arsana, I. G. K., \& Sanjaya, I. P. Y. (2014). PERENCANAAN SISTEM JARINGAN DISTRIBUSI PENYEDIAAN AIR MINUM PEDESAAN DI DESA KUBU KECAMATAN KUBU. Jurnal Ilmiah Teknik Sipil.

[9] Dewi, K. H., Koosdaryani, K., \& Muttaqien, A. Y. (2015). Analisis Kehilangan Air Pada Pipa Jaringan Distribusi Air Bersih PDAM Kecamatan Baki, Kabupaten Sukoharjo. Matriks Teknik Sipil, 3(1).

[10] Wigati, R., Maddeppungeng, A., \& Krisnanto, I. (2015). STUDI ANALISIS KEBUTUHAN AIR BERSIH PEDESAAN SISTEM GRAVITASI MENGGUNAKAN SOFTWARE EPANET 2.0. Konstruksia, 6(2).

[11] Riduan, R., Rusdiansyah, A., \& Suhartanto, E. (2012). Evaluasi Debit dan Tekanan Melalui Simulasi Kebutuhan Air Pada Jaringan Pipa Distribusi Air Bersih Kota Kandangan Propinsi Kalimantan Selatan. Teknologi Kejuruan: Jurnal Teknologi, Kejuruan, dan Pengajarannya, 31(1).

[12] Ramadhan, A. (2014). Analisis Hidrolika Sistem Jaringan Distribusi Air Minum Di Komplek Perumahan PT Pusri Palembang Menggunakan Epanet 2.0. Journal of Civil and Environmental Engineering, 2(3).

[13] Irfan, A. M. (2012). Simulasi Sistem Jaringan Pipa Distribusi Air Bersih Kota Watansoppeng Kabupaten Soppeng. Teknik Mesin"TEKNOLOGI", 12(3 Okt).

[14] Riupassa, H., \& Rahim, A. (2017).SIMULASI CFD DISTRIBUSI TEMPERATUR MENGGUNAKAN ANSYS 14.5 PADA DESTILATOR TENAGA SURYA. Jurnal TEKNIK MESIN, 6(1), 38-46.

[15] Ibrahim, M., Masrevaniah, A., \& Dermawan, V. (2012). Analisa Hidrolis pada Komponen Sistem Distribusi Air Bersih dengan Waternet dan Watercad versi 8 (Studi Kasus Kampung Digiouwa, Kampung Mawa dan Kampung Ikebo, Distrik Kamu, Kabupaten Dogiyai). Jurnal Teknik Pengairan, 2(2), 159-171. 